\title{
High-Precision Determination of the Oxidation State of Komatiite Lavas using Vanadium Liquid-Mineral Partitioning
}

\author{
Robert W. Nicklas ${ }^{1}$, Igor S. Puchtel ${ }^{1}$, and Richard D. Ash ${ }^{1}$ \\ ${ }^{1}$ Department of Geology, University of Maryland, College Park, MD 20742, USA
}

Corresponding author:

Robert William Nicklas; e-mail: rnicklas@umd.edu

\author{
Revised for: \\ Chemical Geology
}

Version 2016/04/07 


\section{Chemical Geology}

\section{Abstract}

Oxygen fugacity of the mantle $\left(f \mathrm{O}_{2}\right)$ is an important intensive variable in Earth sciences that is largely unconstrained throughout Earth history. Oxygen fugacity of modern basalts is determined by examining the $\mathrm{Fe}^{+3} / \mathrm{Fe}^{+2}$ ratios of fresh volcanic glass, but this method cannot be applied to older lavas that have experienced post-magmatic alteration and/or metamorphism.

Here, we report the newly developed analytical techniques that, using the published experimental petrology data, have enabled us to determine the $\mathrm{fO}_{2}$ of mantle-derived lavas with a precision of better than $0.10 \log f \mathrm{O}_{2}$ units. This new method uses the partitioning behavior of the redox-sensitive transition metal vanadium between olivine and/or chromite and komatiitic melt as oxybarometers. In order to obtain accurate and precise results, a series of whole-rock samples was collected across differentiated komatiitic basalt Victoria's Lava Lake in Fennoscandia. Special attention was paid to ensure that the lava contained magmatic olivine and chromite that were in equilibrium with the emplaced melt composition, and that no re-equilibration has occurred during the lava differentiation. Vanadium and other transition metal abundances in the whole-rock samples were determined using standard addition solution ICP-MS technique with a precision of better than 5\% (2SD), and in liquidus olivine and chromite by laser ablation ICP-MS, with a precision of better than 5\% (2SE). The MgO and transition metal abundances in the emplaced komatiitic basalt lava were precisely calculated using several independent approaches; these approaches provided consistent results that agreed within the uncertainty of the method. The partition coefficients $D_{\mathrm{V}}{ }^{\mathrm{Ol} \text {, Chr-Liq }}$ were then calculated and used to determine the $f \mathrm{O}_{2}$ of the lava lake to be $-0.24 \pm 0.04$ and $-0.21 \pm 0.03 \Delta$ NNO log units, respectively (2SE). The two independent estimates are identical within the respective uncertainties and attest to the accuracy of the method; the average value of $-0.22 \pm 0.04 \Delta \mathrm{NNO} \log$ units (2SD) represents our best estimate for the redox state of the lava lake. Corrected for $4 \%$ crustal contamination, the redox state of the original komatiite is calculated to be $-0.29 \pm 0.04 \Delta \mathrm{NNO} \log$ units. The new method provides a high-resolution tool for constraining the evolution of the redox state of the mantle over Earth's history. 


\section{Chemical Geology}

behavior of redox-sensitive elements, such as $\mathrm{Fe}, \mathrm{V}$, and $\mathrm{Cr}$, during igneous differentiation. Unlike many other important variables, oxygen fugacity of the mantle is not well constrained throughout

31 Earth's history. Previous attempts to constrain the evolution of mantle oxygen fugacity have relied on variations in Cr and V contents (Canil, 1997, 1999, 2002; Delano, 2001) and V/Sc ratios (Li and Lee, 2004) of mantle-derived mafic and ultramafic rocks. These studies concluded that, within $\sim 0.5-1.0 \log$ units, oxygen fugacity of the mantle has remained essentially constant since at least the early Archean. The $1.0 \log \mathrm{fO}_{2}$ unit is in itself a very large change in oxygen fugacity and a more precise method for determining the oxidation state of the Archean and post-Archean mantle is needed. Accurate and precise determination of the variations in oxygen fugacity of the mantle throughout Earth's history may also hold the answer to one of the most debated questions in the Earth sciences of why oxygen abundance suddenly rose in the atmosphere at the Archean-Proterozoic boundary (Holland, 2002).

The work of Canil (1997) and Canil and Fedortchouk (2001) demonstrated that the partitioning of V

41 between liquidus olivine and ultramafic melt is a strong function of $f \mathrm{O}_{2}$, with little to no dependence on temperature and melt composition. Further work (Canil, 1999; 2002) demonstrated that the partitioning

43 of $\mathrm{V}$ between liquidus chromite and melt was also a strong function of $f \mathrm{O}_{2}$, although this partitioning is

44 significantly affected by the $\mathrm{Cr} / \mathrm{Al}$ ratio of the system. However, no accurate and precise combined data for $\mathrm{V}$ and $\mathrm{Cr}$ partitioning between olivine, chromite and natural mafic and ultramafic liquids have been reported by far. This is partly due to the scarcity of well-preserved ultramafic lavas in the ancient geological record that would retain primary magmatic minerals suitable for this type of study, and partly 


\section{Chemical Geology}

49 allowed precise and accurate determination of $\mathrm{V}$ abundances in liquidus olivine, chromite, and the

50 ultramafic magmas with which these mineral phases were in equilibrium.

Here, we report the newly developed analytical techniques that, using the experimental petrology data of Canil $(1997,1999,2002)$ and Canil and Fedortchouk (2001), enabled us to determine the $f \mathrm{O}_{2}$ of komatiite lavas with a precision of better than $0.10 \log f \mathrm{O}_{2}$ units. It should be noted, however, that the precision of this method is very case-specific. In addition to our ability to measure $\mathrm{V}$ and other transition metal abundances in whole-rock samples and liquidus olivines and chromites with a sufficiently high degree of precision, it depends heavily on the availability of sufficient amounts of fresh liquidus olivine and/or chromite grains that were in equilibrium with the emplaced komatiite lava, and on the availability and the degree of alteration of samples with a wide range of chemical compositions collected across a single differentiated komatiitic lava flow. If these requirements are not met, it may become impossible to determine $\mathrm{fO}_{2}$ of a komatiite system with any reasonable degree of precision.

The lavas that this method has been developed for are komatiites, ultramafic volcanic rocks having an $\mathrm{MgO}$ content of $>18 \%$ (Arndt and Nisbet, 1982). Komatiites are thought to be the result of either

63 deep, hot, anhydrous melting in mantle plumes (Campbell et al., 1989), with degrees of melting of up to 60\% (Arndt, 1976), or lower-temperature, hydrous melting in a subduction zone environment (Parman et al., 2004). The very high temperatures (up to $1600^{\circ} \mathrm{C}$ ) and low viscosity of dry komatiitic melts enabled them to reach the surface rapidly, with little or no fractionation en route. Once on the surface, komatiite

67 lava flows crystallized only olivine, and some minor chromite at the later stages of differentiation,

68 forming olivine cumulate layers overlain by a zone of olivine- and pyroxene spinifex-textured rocks.

69 Most komatiites are confined to Archean terrains, but Proterozoic and Phanerozoic komatiite

70 occurrences have also been reported (see review in Arndt et al., 2008). Although all komatiites are

71 altered to some degree, in many instances they preserve original, magmatic mineralogy, and some have 


\section{Chemical Geology}

72 even been characterized as "uniquely" (Nisbet et al., 1987) and "remarkably" (Puchtel et al., 1996)

73 fresh, by Archean standards.

\section{Geological background and samples}

75

76

77

78

79

80

81

82

83

84

85

For this study, we chose the remarkably fresh komatiitic basalt lavas of the Victoria's Lava Lake located within the ca. 2.4 Ga Vetreny Belt in SE Fennoscandia (Puchtel et al., 1996, 1997). The $250 \mathrm{~km}$ long Vetreny Belt is considered to be part of the oldest known large igneous province that formed in a continental rift setting, during the interaction of a mantle plume with the Archean continental crust of the Karelian granite-greenstone terrain (Puchtel et al., 1997). Modeling involving lithophile trace element and $\mathrm{Nd}$ isotopic data has shown that komatiitic magmas parental to the Victoria's Lava Lake contained ca. $27 \% \mathrm{MgO}$, and were derived from a long-term LREE-depleted mantle source (Puchtel et al., 1997, 2016). These authors concluded that the chemical evolution of the primary komatiite magmas en route to the surface was controlled by a combination of $\sim 50 \%$ fractional crystallization and $\sim 4.0 \pm 0.4 \%$ assimilation of tonalites from the adjacent $\sim 3.2 \mathrm{Ga}$ Vodla Block. Puchtel et al. (2016) reported Re-Os and Sm-Nd isochron ages for the lava lake of $2407 \pm 6$ and $2403 \pm 32 \mathrm{Ma}$, respectively.

The lava lake is a $\sim 110$ m-deep sequence of komatiitic basalt, which filled a large topographic depression following eruption, and was estimated to have emplaced with $c a .15$ wt.\% MgO (Puchtel et al., 1996, 2016). After emplacement, the lava lake underwent differentiation and developed a prominent internally layered structure comprised of three main units (from the top down): an upper chilled margin, a spinifex zone, and a cumulate zone (Fig. 1). The rocks are characterized by a superb state of preservation; the metamorphic grade did not exceed the prehnite-pumpellyite facies and most magmatic minerals are well preserved. 


\section{Chemical Geology}

For this study, we used the same set of samples collected across several sections of the lava lake and studied by Puchtel et al. (2016). The locations of the samples are shown on the integrated section of the lava lake in Fig. 1.

\section{Analytical techniques}

\subsection{Sample selection}

3.1.1. Whole-rock samples. In order to obtain accurate estimates of emplaced lava composition for a given komatiite lava flow, and to monitor the behavior of petrogenetically important elements during post-magmatic alteration and metamorphism, we studied samples with the widest possible range of $\mathrm{MgO}$ contents. In differentiated komatiite lava units, the most $\mathrm{MgO}$-poor horizons are located at the bottom of spinifex-textured zones, and the most $\mathrm{MgO}$-rich parts are usually located in the lower half of cumulate zones. We also included an upper chilled margin sample, since these normally represent the composition of the emplaced lava from which liquidus olivine crystallized. We, therefore, included samples collected across the entire section of the lava lake, with the $\mathrm{MgO}$ contents ranging from $7.4 \%$ to $27 \%$ (Fig. 1).

3.1.2. Olivine and chromite. In order to determine $\mathrm{V}$ abundances in the liquidus olivine and chromite in equilibrium with the emplaced komatiite lava composition, solid, equant olivine and chromite grains from both the upper chilled margin and the cumulate zone of the lava lake were analyzed in this study (Fig. 2). Based on electron probe analyses, olivines from the chilled margin and the cumulate zone were shown to be in equilibrium with the emplaced lava composition (Puchtel et al., 1996). Chips of the chilled margin sample 12110 and olivine cumulates 12001, 12105, and 12105/1 approximately $10 \mathrm{~mm}$ across were mounted in epoxy, and polished. Pure solid equant chromite grains were separated from the chilled margin sample 12110 and the olivine cumulate samples 12001 and 12105 using conventional magnetic and heavy liquid separation techniques and were also mounted in epoxy and polished.

\subsection{Determination of the emplaced lava composition}

Accurate determination of the composition of the emplaced komatiite lava is crucial for evaluating $\mathrm{V}$ partitioning behavior between liquidus olivine, chromite and the melt from which they crystallized. In order to calculate the $\mathrm{MgO}$ content of the emplaced lava, Puchtel et al. $(1996,2016)$ used several independent approaches.

The first approach used the composition of the upper chilled margin as a proxy for the parental liquid composition. This approach is based on the fact that upper chilled margins of komatiite lava flows likely crystallized rapidly. Consistent with this, they usually do not show evidence of differentiation after emplacement, although some may contain a small amount of olivine phenocrysts (Arndt, 1986).

The second approach is based on the well-established relationship between the composition of olivine and that of the liquid from which it crystallized (Roeder and Emslie, 1970; Beattie et al., 1991). The maximum average MgO and minimum $\mathrm{FeO}$ contents of the cores of the cumulate olivine grains and olivine phenocrysts in the upper chilled margin of the Victoria's Lava Lake were determined and the composition of the komatiite liquid in equilibrium with these olivine compositions was 


\section{Chemical Geology}

estimated using the partition coefficients from Beattie et al. (1991). Further, the compositions of the chilled margin derived from approach (1) and that of the emplaced lava derived from approach (2) were tested for consistency.

Finally, the third approach required calculation of the average $\mathrm{MgO}$ content of liquidus olivine in equilibrium with the emplaced lava by means of regressing the abundances of the elements that are incompatible with olivine, against the $\mathrm{MgO}$ contents; the intersections with the $\mathrm{MgO}$ axis corresponded to the average $\mathrm{MgO}$ content in the liquidus olivine. The average calculated $\mathrm{MgO}$ content of the liquidus olivine was then used to back-calculate the $\mathrm{MgO}$ content of the emplaced lava using approach (2). The $\mathrm{MgO}$ contents obtained using the three independent approaches were then averaged to yield the $\mathrm{MgO}$ content of the emplaced komatiite lava.

\subsection{Analysis of major and minor elements in whole-rock samples}

Major-element analyses of whole rock komatiite samples were carried out at Franklin \& Marshall College on fused glass discs using a Phillips 2404 XRF spectrometer, following the procedure of Mertzman (2000). Typical accuracy of the analyses was $\sim 1 \%$ relative for major elements with concentrations $>0.5 \%$ and $\sim 5 \%$ relative for the other major elements. In this study, we used the major element data obtained by Puchtel et al. (2016) for the set of samples studied here.

\subsection{Electron microprobe analysis of olivine and chromite}

Major element analyses of olivines were performed on polished thin sections using the JEOL JXA 8900 R electron probe microanalyzer at the Center for Microanalysis, University of Maryland. Special attention was paid to select and analyze only early-crystallized, solid equant grains that were likely in equilibrium with the emplaced Victoria's Lava Lake lava. Operating conditions were $15 \mathrm{KeV}$ accelerating potential, a $20 \mathrm{nA}$ focused electron beam current, and a $10 \mu \mathrm{m}$ spot size. Major element analyses of epoxy-mounted chromite separates were performed under the same conditions. These electron probe data were then used for data normalization purposes for the laser ablation analysis, as specified below.

\subsection{Analysis of transition metal abundances in whole-rock samples}

The abundances of the transition metals in whole-rock samples were determined using the standard addition solution inductively-coupled plasma mass-spectrometry technique (SA ICP-MS). Between 25 and $35 \mathrm{mg}$ of sample powder, $0.5 \mathrm{~mL}$ double-distilled conc. $\mathrm{HNO}_{3}$ and $3 \mathrm{~mL}$ double-distilled conc. HF were weighed out in $15 \mathrm{~mL}$ screw-cap Savillex Teflon vials, sealed using Teflon tape, and kept on a hotplate at $200^{\circ} \mathrm{C}$ for 48 hours. The vials were then opened, the sample solutions evaporated to dryness, $0.5 \mathrm{~mL}$ of distilled SeaStar $\mathrm{HClO}_{4}$ was added to the dry residue to convert fluorides into perchlorides. The vials were sealed again and kept on the hotplate at $200^{\circ} \mathrm{C}$ for 48 hours. The vials were then opened and the sample solutions dried down on the hotplate at $230^{\circ} \mathrm{C}$. This step was followed by re-dissolution of the residue in $2-3 \mathrm{~mL}$ of $6 \mathrm{M} \mathrm{HCl}$ to convert it into the chloride form, and dried down. This step was repeated twice. The dry residue was then taken up in $\sim 10$ grams of $0.8 \mathrm{M} \mathrm{HNO}_{3}$ and this stock solution was used for preparing spiked aliquots used for the ICP-MS measurements. A standard addition spike was prepared, containing concentrated mixed solutions of $\mathrm{Sc}, \mathrm{V}, \mathrm{Cu}, \mathrm{Co}, \mathrm{Ga}, \mathrm{Y}$, and $\mathrm{Zr}$. Three aliquots of each sample, each containing $0.5-1.0 \mathrm{~mL}$ of sample stock solution, were prepared, one containing no spike, one with the amount of spike $2 \times$ the estimated amount of element present in the sample aliquot, and one with the amount of spike $4 \times$ the estimated amount of element present in the sample aliquot. One total analytical blank (TAB) was also prepared and 


\section{Chemical Geology}

measured with every batch of 6 samples. Approximately $100 \mathrm{mg}$ of $500 \mathrm{ppb}$ In solution was added to each sample aliquot and the $\mathrm{TAB}$ solutions to monitor and correct for the signal drift during the analysis, and the three mixed solutions for each sample were diluted to 10 grams using $0.8 \mathrm{~N} \mathrm{HNO}_{3}$.

The sample solutions were analyzed on a ThermoFinnigan Element 2 sector field inductively-coupled plasma massspectrometer (ICP-MS) at the Plasma Laboratory, Department of Geology, University of Maryland. Prior to analysis, the instrument was thoroughly tuned to maximize sensitivity and minimize oxide production, and mass-calibrated. The intensities of selected isotopes of each element were measured in both low- and medium resolution modes. The raw data were reduced using an in-house Excel macro. The in-run uncertainties on the concentrations were typically better than $2 \%$ for all elements (2SE). The external precision of the analysis was determined via the analysis of USGS standard reference materials (SRM) BIR-1, BHVO-1, and BCR-1; for most elements, including V, it was between 2 and 5\% (2SD) and included the uncertainty introduced by sample powder heterogeneity (Tables 1-3, Fig. 3). The largest of the 2SD uncertainties (5\%) obtained for the three USGS SRM was used as a measure of uncertainty on the transition metal abundances for the individual whole-rock samples. These 2SD uncertainties were further used for the ISOPLOT regression calculations.

\subsection{Laser ablation analysis of liquidus olivine and chromite}

Several chips ( $1 \mathrm{~cm}$ across) of the chilled margin sample 12110 and of olivine cumulates 12001, 12105, and 12105/1, as well as pure chromite separates from these samples, were selected for analysis. A total of 133 olivine grains and 139 chromite grains were analyzed using a UP213 New Wave laser-ablation system coupled to the ThermoFinnigan Element2 ICP-MS at the Plasma Laboratory, Deparment of Geology, University of Maryland. The quintupled Nd-YAG laser operated at $\sim 60 \%$ power and $7 \mathrm{~Hz}$ with fluence controlled between $2-4 \mathrm{~J} / \mathrm{cm}^{2}$ ( $\sim 60 \%$ laser power). The spot size of each analysis varied between 55 and $100 \mu \mathrm{m}$ for the olivines and 25-40 $\mu \mathrm{m}$ for the chromites, depending on the size of the grains being analyzed. Only solid, equant olivine and chromite grains containing no visible inclusions were selected for analysis (Fig. 2). Replicate analyses of the USGS SRM BHVO-2G and BCR-2G were performed with each set of 12-16 spots analyzed. The raw data were reduced using the in-house LAMTRACE software, using either the $\mathrm{FeO}$ abundances for liquidus olivine in equilibrium with the emplaced komatiite lava or average $\mathrm{FeO}$ for the population of chromite grains for each particular sample obtained from the electron microprobe analyses, as normalizing values.

Based on the available major and minor element abundance data for the studied olivine and chromite (e.g., Puchtel et al., 1996, and this study), variations in the abundances of these elements within individual samples are estimated to not exceed $5 \%$ relative, implying rather homogenous compositions of the solid equant olivine and chromite grains selected for analysis. Based on this observation, it is assumed that all the variations in $\mathrm{V}$ and other transition metal abundances in the studied populations of olivine and chromite grains within the same samples reflect the analytical uncertainty of the LA-ICP-MS analysis. As such, the 2SE was used as the measure of the uncertainty on the calculated average concentrations of transition metals in either olivine or chromite for the individual samples (Figs. 4 and 5). For V concentrations, these uncertainties were 
$\sim 5 \%$ for the olivine, and between 2 and 3\% for the chromite. For the ISOPLOT regression calculations, the 2SD uncertainty on the average transition metal abundances in the studied olivine and chromite samples was used.

\section{Results}

\subsection{Compositions of the emplaced komatiitic basalt lava and of the liquidus olivine and} chromite

Transition metal abundance data for the whole-rock samples analyzed in this study are presented in

Table 4, and for the liquidus olivines and chromites in Table 5. The V abundances in the individual olivine and chromite grains analyzed in this study are also plotted in Figs. $\mathbf{4}$ and 5, respectively.

The average $\mathrm{V}$ abundances in the liquidus olivines are $7.82 \pm 0.39 \mathrm{ppm}$ in the chilled margin sample 12110 and $7.31 \pm 0.39,7.21 \pm 0.36$, and $7.18 \pm 0.36 \mathrm{ppm}$ in the olivine cumulate samples 12001,12105 , and $12105 / 1$, respectively (2SE). The average $\mathrm{V}$ abundances in the liquidus chromites are $1378 \pm 40 \mathrm{ppm}$ in the chilled margin sample 12110 , and $1395 \pm 28$ and $1394 \pm 25 \mathrm{ppm}$ in the olivine cumulate samples 12001 and 12105, respectively (2SE). It is important to note that the average V abundances for both olivines and chromites are identical between different cumulate samples collected across the lava lake. Even more importantly, the average $\mathrm{V}$ abundances in both olivine and chromite grains from the chilled margin and the cumulate zone samples are also identical, within their respective uncertainties.

\section{4 metamorphism of the lava lake, of all the transition metals analyzed in this study. This conclusion is}




\section{Chemical Geology}

215 consistent with the findings of Puchtel et al. $(1996,2016)$ regarding immobile behavior of lithophile 216 trace and highly siderophile elements that those authors studied.

217 In order to estimate the composition of the emplaced komatiitic basalt lava, several independent 218 approaches were used, as outlined in the section on Analytical Techniques. Samples 91110, 01110/1, 219 and 12110/1 collected from the upper chilled margin of the lava lake (Puchtel et al., 1996; 2016) are 220 glassy rocks composed of $\sim 15 \%$ euhedral olivine phenocrysts in a quenched groundmass of olivine 221 microphenocrysts, cruciform and euhedral chromite grains, and devitrified glass. This part of the lava 222 lake must have crystallized very quickly. It did not undergo any post-eruption differentiation and is 223 interpreted to have a bulk composition very similar to that of the komatiitic basalt liquid from which the 224 lava lake formed. The average $\mathrm{MgO}$ content of the three samples is $14.65 \pm 0.04 \mathrm{wt} \% \mathrm{MgO}$ (2SD).

The second approach to estimate the composition of the emplaced komatiitic basalt lava was based on the relationship between the composition of olivine and that of the liquid from which it crystallized (Beattie et al., 1991). The most magnesian olivines (Fo88.7-88.9) were documented in the upper and lower chilled margins of the lava lake (Puchtel et al., 1996). Using a $D^{\mathrm{Mg}-\mathrm{Fe}}$ Ol-Liq $=0.31$ (Beattie et al., 1991) and the $\mathrm{Mg} / \mathrm{Fe}$ ratio in the emplaced komatiite lava from Puchtel et al. (1996; 2016), these olivines were calculated to have been in equilibrium with a liquid containing $15.0 \pm 0.4 \mathrm{wt}$ \% $\mathrm{MgO}$ (2SD).

Finally, the liquidus olivine composition was inferred using an indirect approach based on the general differentiation trends established for the lava lake. In the plots of $\mathrm{MgO}$ versus an element that is excluded from the olivine crystal lattice, the analytical data for samples containing different proportions of olivine crystallized from the emplaced komatiitic basalt lava must plot on the mixing lines, a.k.a. olivine control lines. The intercepts of these regression lines with the $\mathrm{MgO}$ axis correspond directly to the average composition of liquidus olivine. Using regressions for the incompatible lithophile trace element data from Puchtel et al. $(1996 ; 2016)$, the average MgO content of the liquidus olivine has been 


\section{Chemical Geology}

238

calculated to be $47.8 \pm 0.5 \% \mathrm{MgO}$. Recalculating for the olivine stoichiometry, this gives an olivine composition of $\mathrm{Fo}_{88.7}$, in excellent agreement with the results of the olivine microprobe studies. This result also implies equilibrium between liquidus olivine and the emplaced lava in terms of the $\mathrm{Mg}$-Fe relationship. Thus, the three independent approaches yield an average $\mathrm{MgO}$ content of the emplaced komatiitic basalt lava of $14.8 \pm 0.3$ wt. \% (2SD).

Using the estimated $\mathrm{MgO}$ content of the emplaced komatiitic basalt lava of $14.8 \pm 0.3 \mathrm{wt} . \%$ and ISOPLOT regression analysis, we calculated abundances of the transition metals in the emplaced komatiitic basalt lava; these data are reported in Table 4. These calculations gave the V content of $192 \pm 4 \mathrm{ppm}$. The average V contents of the liquidus olivines and chromites from the lava lake are calculated to be $7.38 \pm 0.30$ and $1389 \pm 11 \mathrm{ppm}$, respectively, and the average Sc abundances are calculated to be $5.66 \pm 0.67$ and $7.6 \pm 1.1 \mathrm{ppm}$, respectively. These data, thus, yielded the following liquidus mineral/komatiitic basalt melt partition coefficients for $\mathrm{V}$ and Sc: $D_{\mathrm{V}}{ }^{\mathrm{Ol}-\mathrm{Liq}}=0.0385 \pm 0.0009$ and $D_{\mathrm{V}}{ }^{\text {Chr-Liq }}=7.25 \pm 0.16 ; D_{\mathrm{Sc}}{ }^{\text {Ol-Liq }}=0.174 \pm 0.006$ and $D_{\mathrm{Sc}}^{\text {Chr-Liq }}=0.236 \pm 0.007$. It is noteworthy that there are substantial differences in $\mathrm{V}$ and Sc partitioning behavior between olivine, chromite, and komatiitic melt. As a result, fractionation of chromite and olivine may have appreciable effect on the V/Sc ratio in the komatiitic and basaltic systems. In this study, we did not use the V/Sc systematics of the Victoria's Lava Lake to evaluate its redox state.

\subsection{Evaluation of the redox state of the Victoria's Lava Lake system}

Having determined the $\mathrm{V}$ partition coefficients between the liquidus olivine, chromite and the komatiitic basalt melt of the Victoria's Lava Lake, we used the experimental calibrations of Canil (1997, 1999; 2002) and Canil and Fedortchouk (2001) to evaluate the oxidation state of the komatiite system.

Regressions of the experimental data yielded $\log \left(D_{\mathrm{v}}{ }^{\mathrm{Ol}-\mathrm{Liq}}\right)=-0.2416 \times \Delta \mathrm{NNO}-1.4796\left(\mathrm{r}^{2}=0.94\right)$ for the olivines (Canil, 1997; Canil and Fedortchouk, 2001), and $D_{\mathrm{V}}{ }^{\text {Chr-Liq }}=-5.442 *(\Delta \mathrm{NNO})+6.1143\left(\mathrm{r}^{2}=0.97\right)$ 


\section{Chemical Geology}

261 for the chromites (Canil, 1999). Though partitioning behavior of $\mathrm{V}$ has been shown to have little to no 262 dependence on temperature, pressure, or melt composition, $D_{\mathrm{V}}{ }^{\text {Chr-Liq }}$ is known to depend strongly on the

$263 \mathrm{Cr} / \mathrm{Al}$ ratio of the system (Canil, 2002). For our calculations, we used the experimental calibration curve 264 for komatiitic composition "komv" of Canil (1999). This composition was selected due to the fact that, 265 among all experimental compositions studied by Canil $(1999,2002)$, it had the $\mathrm{Cr} / \mathrm{Al}$ ratio that was most 266 similar to that of the emplaced komatiitic basalt of the lava lake. units, and the $\mathrm{fO}_{2}$ value calculated from the $\mathrm{V}$ partitioning data for the chromite is $-0.21 \pm 0.03 \Delta \mathrm{NNO}$ $\log$ units. The two independently obtained $\mathrm{fO}_{2}$ values overlap within the respective uncertainties; the average $f \mathrm{O}_{2}$ value of $-0.22 \pm 0.04$ (2SD) represents our best estimate for the redox state of the Victoria's

271 Lava Lake.

\section{Discussion}

\subsection{Effects of secondary alteration, re-equilibration, and crustal contamination}

\subsubsection{Secondary alteration}

All komatiite lavas are altered to a greater or lesser degree as a result of interaction with seawater, as almost all were erupted subaqueously including the Victoria's Lava Lake, and also by subsequent metamorphism. Secondary alteration may result in post-magmatic re-distribution of petrogenetically important elements, including V, which, in turn, may have affected the estimates for V (and other transition metal) abundances in the emplaced komatiite lava. One way to test whether an element has been affected by postmagmatic processes is to plot its abundances against indices of magmatic

281 differentiation, such as the $\mathrm{MgO}$ content (Arndt, 1986). Since the only liquidus phase present in 282 komatiite lavas over a large range of temperatures and compositions is olivine, accompanied by minor 283 chromite in lavas with less than 20-24\% MgO depending on the oxidation state of the system (Barnes, 


\section{Chemical Geology}

284 1998), samples with primary, magmatic distribution of the elements of interest should plot on olivine 285 control lines. In case of the Victoria's Lava Lake, immobile behavior of most major, minor, and trace 286 elements has been well documented (e.g., Puchtel et al., 1996, 2016). In this study, abundances of all 287 transition metals are strongly inversely correlated with $\mathrm{MgO}$ content and follow olivine control lines 288 (Fig. 6), providing evidence for immobile behavior of these elements during alteration.

\subsubsection{Mineral re-equilibration}

The method to determine the redox state of a komatiite system used in this study requires liquidus

291 olivine and chromite to be in equilibrium with the emplaced komatiite lava. Although olivine and 292 chromite phenocrysts found in the upper chilled margins of komatiite lava flows likely preserve their 293 original V partitioning characteristics due to the very quick solidification of this part of the lava flows 294 (e.g., Arndt, 1986), olivine and chromite from cumulate parts, which take longer to crystallize, may a very minor role during differentiation and crystallization of the Victoria's Lava Lake. experience re-equilibration with the residual liquid (Barnes, 1998). In this study, several lines of evidence indicate that $\mathrm{V}$ re-equilibration between the olivine, chromite, and the komatiitic liquid played

First, we analyzed only cores of solid, equant grains that were shown to be in equilibrium with the emplaced komatiite lava for major elements (Puchtel et al., 1996). These cores of olivine and chromite grains, analyzed in samples collected across the lava lake, have similar V abundances between the samples, and little variations among the grains from the same samples, reflected in rather small uncertainties on the averages for individual samples.

Second, both olivine and chromite grains in the chilled margin sample 12110 have average V abundances identical to those of olivine and chromite grains in samples from the cumulate portion of the lava lake. Since the upper chilled margin of the lava lake most likely crystallized almost instantaneously as a result of intensive heat dissipation caused by turbulent flow and interaction with seawater (Huppert 


\section{Chemical Geology}

307 et al., 1984; Huppert and Sparks, 1985b), as also evidenced by its essentially glassy texture (Puchtel et

$308 a l ., 1996)$, it is very unlikely that the olivine and chromite grains from the cumulate zone of the lava lake

309 would have retained the same $\mathrm{V}$ abundances as the olivine and chromite phenocrysts from the upper

310 chilled margin, should any re-equilibration have taken place.

311 Finally, the consistency of the independent estimates of the redox state of the Victoria's Lava Lake

312 system calculated on the basis of the olivine and chromite oxybarometers strongly argue against any late 313 re-equilibration.

\subsubsection{Crustal contamination}

315 Due to their extremely high liquidus temperatures, in many instances exceeding $1600^{\circ} \mathrm{C}$, and low 316 viscosities, komatiitic magmas are known to be able to assimilate up to $40 \%$ of country rocks on their 317 way to the surface (Huppert and Sparks, 1985a) and up to $10 \%$ via thermal erosion after emplacement 318 (Huppert and Sparks, 1985b). Due to one- to two orders of magnitude lower concentrations of lithophile 319 trace elements in komatiitic magmas compared to upper crustal materials, crustal contamination may 320 result in substantial changes in lithophile trace element and isotopic parameters of original komatiite 321 magmas. Based on lithophile trace element data, Puchtel et al. (1996, 2016) calculated that the emplaced 322 lava of the Victoria's Lava Lake was derived from a komatiite magma containing ca. $27 \% \mathrm{MgO}$ via the 323 combination of ca. $50 \%$ fractional crystallization and assimilation of $4.0 \pm 0.4 \%$ felsic crustal material of 324 the adjacent Vodla Block tonalites. Although fractionation of olivine and minor chromite is not expected 325 to cause any changes in the redox state of the original komatiite magma, the effects of assimilation of 326 the tonalites must be evaluated and accounted for.

327 For the purpose of modeling, we assumed simple mixing between a tonalite endmember and the 328 original komatiite magma parental to the Victoria's Lava Lake komatiitic basalt. As an estimate for the 329 redox state of the tonalite endmember, we used an average $f \mathrm{O}_{2}(+0.5 \Delta \mathrm{NNO} \log$ units $)$ of the andesitic 


\section{Chemical Geology}

330 continental crust produced at modern island arcs (Carmichael, 1991). Using the $f \mathrm{O}_{2}$ of the contaminated

331 Victoria's Lava Lake komatiite of $-0.22 \pm 0.04 \Delta \mathrm{NNO} \log$ units, addition of $4.0 \mathrm{wt} . \%$ of the tonalitic

332 endmember is calculated to result in an increase in the oxygen fugacity of the original komatiite lava by

$3330.07 \triangle \mathrm{NNO} \log$ units. Even though the redox state of the Archean continental crust is currently not very

334 well constrained and may slightly differ from the redox state of the modern continental crust, it was

335 likely less oxidized due to the more reducing atmosphere in the Archean compared to the present. As

336 such, this shift in the redox state of the original komatiite magma of $0.07 \Delta \mathrm{NNO}$ log units represents the

337 maximum estimate. Assuming a rather conservative 50\% uncertainty on this estimate from the range in

338 crustal $f \mathrm{O}_{2}$, crustal contamination is calculated to increase the oxidation state of the Victoria's Lave

339 Lake system by $0.07 \pm 0.04 \Delta \mathrm{NNO} \log$ units. Corrected for the effects of crustal contamination, the

340 estimated redox state of the komatiite system is, thus, calculated to be $-0.29 \pm 0.04 \Delta \mathrm{NNO} \log$ units.

\subsection{The significance of the redox data for the Victoria's Lava Lake}

Based on the argument presented above, we conclude that the redox state of the Victoria's Lava

344 and chromite oxybarometers and corrected for crustal contamination, represents our best estimate for the 345 redox state of the Victoria's Lava Lake primary komatiite magma. The uncertainty on this estimate is at 346 least a factor of 10 smaller than those reported in the previous studies (Canil, 1997; Delano, 2001; Li 347 and Lee, 2004).

348 Even though the absolute uncertainty on the estimate for the redox state of a komatiite system 349 reached in this study is ca. $0.04 \Delta \mathrm{NNO} \log$ units, it still can be affected by the absolute uncertainties on 350 the experimental calibrations of both the olivine and chromite oxybarometers, which can be as large as $3510.20 \Delta$ NNO log units (Canil, 1999; Canil and Fedortchouk, 2001). However, since uncertainties on the 352 relative estimates for redox states of different komatiite systems are insensitive to the uncertainties in the 


\section{Chemical Geology}

353 experimental calibrations, this method provides a high-resolution, accurate tool for constraining the 354 evolution of mantle oxygen fugacity over Earth's history.

\section{Concluding remarks}

Komatiites represent a valuable tool for studying Earth's interior, especially during the first 2 billion years of Earth's history. This study reports details of a newly developed high-resolution method for determining redox state of komatiite lavas with a precision of better than $0.10 \Delta \mathrm{NNO} \log$ units.

The new method uses the partitioning behavior of the redox-sensitive transition metal vanadium between olivine, chromite and komatiitic melt as oxybarometers, and the experimental calibrations of Canil (1997), Canil and Fedortchouk (2001) and Canil (1999, 2002). In order for this methodology to produce accurate and precise results, several important conditions must be met.

First, V must be shown to be immobile during secondary alteration and metamorphism of the selected komatiite lava. This is accomplished via systematic collection of a series of samples across differentiated komatiite lava flow(s), obtaining high-precision whole-rock major element and V (and other transition metal) concentration data using standard addition ICP-MS, and regressing these data against indices of magmatic differentiation (e.g., $\mathrm{MgO}$ content) to establish the magmatic nature of the variations in $\mathrm{V}$ abundances across the lava flows. Second, $\mathrm{MgO}, \mathrm{V}$, and other transition metal abundances in the emplaced komatiite lava must be precisely calculated using several independent approaches; these approaches should provide consistent results that must agree within the uncertainty of the method. Third, the komatiite lavas of interest must contain sufficient amounts of liquidus olivine and/or chromite and these must be shown to be in equilibrium with the emplaced komatiite lava. A special attention must be paid to ensure that no re-equilibration has occurred during differentiation of the komatiite lava units, which can be achieved via analyzing only cores of solid, equant olivine and/or 


\section{Chemical Geology}

375 chromite grains from both upper chilled margins and cumulate layers of lava flows and closely

376 monitoring the consistency between their chemical compositions. Finally, laser ablation ICP-MS

377 analyses of the olivine and/or chromite grains must be performed to determine V (and other transition

378 metal) concentrations with the highest possible precision and accuracy, which is achieved via analyzing

379 sufficiently large number of inclusion-free grains.

380 The independent olivine and chromite oxybarometers studied here yielded results that overlapped 381 within the respective uncertainties, attesting to the accuracy of the redox data obtained for the lava lake.

382 Even though the uncertainty on the oxygen fugacity of a komatiite system reached in this study is ca.

$3830.04 \Delta \mathrm{NNO}$ log units, it still can be affected by the absolute uncertainty on the experimental calibrations 384 of the olivine and chromite oxybarometers, which can be as large as $0.20 \Delta$ NNO log units (Canil, 1999; 385 Canil and Fedortchouk, 2001). However, since uncertainties on the relative estimates for redox states of 386 different komatiite systems are insensitive to the uncertainties in the experimental calibrations, this 387 method provides a high-resolution tool for constraining evolution of the redox state of the mantle over 388 Earth's history.

\section{Acknowledgments}

390 This study was supported by NSF FESD Type I Grant \#1338810 “The Dynamics of Earth System 391 Oxygenation" (lead PI is A.D. Anbar, I.S. Puchtel is a co-PI). This source of support is gratefully 392 acknowledged. We thank Cin Ty Lee, Dante Canil, and Fabrice Gaillard for constructive reviews that 393 helped improve the original version of the manuscript, and Catherine Chauvel for editorial handling. We 394 also thank Valentina Puchtel for help with sample preparation for the ICP-MS analyses.

\section{References}


398

Arndt, N.T., 1986. Differentiation of komatiite flows. Journal of Petrology 27(2): 279-301.

Arndt, N.T., Lesher, C.M., and Barnes, S.J. (2008). Komatiite. Cambridge, UK, Cambridge University Press.

Arndt, N.T., and Nisbet, E.G. (1982). What is a komatiite? Komatiites. Arndt, N.T. and Nisbet, E.G. London, George Allen and Unwin: 19-28.

Barnes, S.J., 1998. Chromite in komatiites, I. Magmatic controls on crystallization and composition. Journal of Petrology 39(10): 1689-1720.

Barnes, S.J., Hill, R.E.T., and Gole, M.J., 1988. The Perseverance ultramafic complex, Western Australia: the product of a komatiite lava river. Journal of Petrology 29(2): 305-331.

Beattie, P., Ford, C., and Russell, D., 1991. Partition coefficients for olivine-melt and orthopyroxenemelt systems. Contributions to Mineralogy and Petrology 109(2): 212-224.

Campbell, I.H., Griffiths, R.W., Hill, R.I. (1989). Melting in an Archean Mantle Plume: heads it's basalts, tails it's komatiites. Nature 339: 697-699.

Canil, D., 1997. Vanadium partitioning and the oxidation state of Archaean komatiite magmas. Nature 389(6653): 842-845.

Canil, D., 1999. Vanadium partitioning between orthopyroxene, spinel and silicate melt and the redox states of mantle source regions for primary magmas. Geochimica et Cosmochimica Acta 63(3-4): 557-572.

Canil, D., and Fedortchouk, Y., 2001. Olivine-liquid partitioning of vanadium and other trace elements, with applications to modern and ancient picrites. Canadian Mineralogist 39: 319-330.

Canil, D., 2002. Vanadium in peridotites, mantle redox and tectonic environments: Archean to present. Earth and Planetary Science Letters 195(1-2): 75-90.

Carmichael, I.S.E., 1991. The redox states of basic and silicic magmas: a reflection of their source regions? Contributions to Mineralogy and Petrology 106(2): 129-141.

Cottrell, E., and Kelley, K.A., 2011. The oxidation state of Fe in MORB glasses and the oxygen fugacity of the upper mantle. Earth and Planetary Science Letters 305(3-4): 270-282.

Cottrell, E., Kelley, K.A., Lanzirotti, A., and Fischer, R.A., 2009. High-precision determination of iron oxidation state in silicate glasses using XANES. Chemical Geology 268(3-4): 167-179.

Delano, J.W., 2001. Redox History of the Earth's Interior since 3900 Ma: Implications for Prebiotic Molecules. Origins of life and evolution of the biosphere 31(4-5): 311-341.

Farquhar, J., Bao, H., and Thiemens, M., 2000. Atmospheric influence of Earth's earliest sulfur cycle. Science 289(5480): 756-758.

Huppert, H.E., and Sparks, R.S.J., 1985a. Cooling and contamination of mafic and ultramafic magmas during ascent through continental crust. Earth and Planetary Science Letterrs 74(4): 371-386.

Huppert, H.E., and Sparks, R.S.J., 1985b. Komatiites I: Eruption and flow. Journal of Petrology 26(3): 694-725.

Huppert, H.E., Sparks, R.S.J., Turner, J.S., and Arndt, N.T., 1984. Emplacement and cooling of komatiite lavas. Nature 309(5963): 19-22.

Li, Z.X.A., and Lee, C.T.A., 2004. The constancy of upper mantle $f \mathrm{O}_{2}$ through time inferred from V/Sc ratios in basalts. Earth and Planetary Science Letters 228(3-4): 483-493.

Lyons, T.W., Reinhard, C.T., and Planavsky, N.J., 2014. The rise of oxygen in Earth's early ocean and atmosphere. Nature 506(7488): 307-315.

Mertzman, S.A., 2000. K-Ar results from the southern Oregon - northern California Cascade range. Oregon Geology 62(4): 99-122. 
442 Nisbet, E.G., Arndt, N.T., Bickle, M.J., Cameron, W.E., Chauvel, C., Cheadle, M., Hegner, E., Kyser, T.K., Martin, A., Renner, R., and Roedder, E., 1987. Uniquely fresh 2.7 Ga komatiites from the Belingwe greenstone belt, Zimbabwe. Geology 15(12): 1147-1150.

Parman, S.W., Grove, T.L., Dann, J.C., and de Wit, M.J., 2004. A subduction origin for komatiites and cratonic lithospheric mantle. South African Journal of Geology 107(1-2): 107-118.

Puchtel, I.S., Haase, K.M., Hofmann, A.W., Chauvel, C., Kulikov, V.S., Garbe-Schönberg, C.D., and Nemchin, A.A., 1997. Petrology and geochemistry of crustally contaminated komatiitic basalts from the Vetreny Belt, southeastern Baltic Shield: Evidence for an early Proterozoic mantle plume beneath rifted Archean continental lithosphere. Geochimica et Cosmochimica Acta 61(6): 1205-1222.

Puchtel, I.S., Hofmann, A.W., Mezger, K., Shchipansky, A.A., Kulikov, V.S., and Kulikova, V.V., 1996. Petrology of a 2.41 Ga remarkably fresh komatiitic basalt lava lake in Lion Hills, central Vetreny Belt, Baltic Shield. Contributions to Mineralogy and Petrology 124: 273-290.

Puchtel, I.S., Touboul, M., Blichert-Toft, J., Walker, R.J., Brandon, A.D., Nicklas, R.W., Kulikov, V.S., and Samsonov, A.V., 2016. Lithophile and siderophile element systematics of the mantle at the Archean-Proterozoic boundary: Evidence from 2.4 Ga komatiites. Geochimica et Cosmochimica Acta 180: 227-255.

Roeder, P.L., and Emslie, R.F., 1970. Olivine-liquid equilibrium. Contributions to Mineralogy and 461 


\section{Figure captions}

Fig. 1. Schematic integrated section through the Victoria's Lava Lake showing textural variations within the lake and location of the samples analyzed in this study. The MgO contents of the individual samples (wt.\%) are shown in parentheses.

Fig. 2. Photomicrographs of the upper chilled margin sample $12110(\boldsymbol{a})$ and the olivine cumulate sample 12105 (b) showing the type of solid equant olivine grains analyzed in this study. Clearly visible are rounded laser ablation pits within the grains analyzed. The fields of view are $3.0 \times 2.5$ $\mathrm{mm}$; cross-polarized light.

Fig. 3. Vanadium, Sc, and Ga abundances in replicate digestions of the USGS standards BIR-1, BHVO1, and BCR-1 determined using standard addition solution ICP-MS. The external reproducibility (2SD) is listed for each element. The GEOREM preferred values for each standard are provided for reference.

Fig. 4. Laser ablation ICP-MS data for cores of solid, equant olivine grains from the chilled margin sample 12110 and olivine cumulate samples 12001, 12105, and 12105/1. The uncertainty on the concentrations is $2 \mathrm{SE}$. Note the consistency of the average $\mathrm{V}$ abundances between samples collected from different parts of the lava lake.

Fig. 5. Laser ablation ICP-MS data for solid, equant chromite grains from the chilled margin sample 12110 and olivine cumulate samples 12001 and 12105. The uncertainty on the concentrations is 2SE. Note that, similarly to the olivine grains analyzed, chromite grains from the different parts of the lava lake have average $\mathrm{V}$ concentrations that are identical within the uncertainty.

Fig. 6. Concentrations of selected lithophile trace elements and transition metals (ppm) plotted against $\mathrm{MgO}$ contents (wt.\%) for the whole rock samples and liquidus olivines of the Victoria's Lava Lake. All data plot on the tight, well constrained trends corresponding to olivine control lines, indicating that olivine was the only major fractionating phase controlling variations of these elements during differentiation of the lava lake, and that the samples fully retained their primary, igneous signatures with respect to concentrations of these elements. 
Table 1. Transition metal abundances (ppm) in USGS SRM BIR-1 obtained via the SA ICP-MS analysis technique. The GEOREM preferred values and the uncertainties ( $\pm 2 \mathrm{SD})$ are listed at the bottom.

\begin{tabular}{|c|c|c|c|c|c|c|}
\hline SRM & Sc & $\mathrm{V}$ & $\mathrm{Cu}$ & $\mathbf{G a}$ & $\mathbf{Y}$ & $\mathrm{Zr}$ \\
\hline BIR1-01 & 44.2 & 323 & 125 & 16.0 & 15.2 & 16.9 \\
\hline BIR1-02 & 42.8 & 310 & 122 & 15.7 & 14.5 & 16.0 \\
\hline BIR1-03 & 43.9 & 316 & 126 & 16.1 & 14.8 & 15.5 \\
\hline BIR1-04 & 44.8 & 322 & 126 & 16.2 & 15.0 & 15.9 \\
\hline BIR1-05 & 43.1 & 313 & 123 & 15.5 & 14.6 & 17.0 \\
\hline BIR1-06 & 43.3 & 317 & 122 & 15.5 & 14.7 & 16.7 \\
\hline BIR1-07 & 45.3 & 331 & 131 & 15.6 & 14.7 & 16.1 \\
\hline BIR1-08 & 42.7 & 326 & 130 & 15.6 & 15.2 & 16.0 \\
\hline BIR1-09 & 43.0 & 310 & 126 & 15.5 & 14.6 & 16.3 \\
\hline BIR1-10 & 44.8 & 333 & 135 & 17.1 & 15.1 & 17.0 \\
\hline BIR1-11 & 42.5 & 307 & 119 & 14.9 & 14.6 & 15.5 \\
\hline BIR1-12 & 44.8 & 335 & 132 & 17.0 & 15.5 & 16.1 \\
\hline BIR1-13 & 43.7 & 315 & 131 & 16.1 & 15.2 & 16.0 \\
\hline BIR1-14 & 46.1 & 319 & 133 & 17.0 & 15.5 & 16.2 \\
\hline BIR1-15 & 46.4 & 322 & 144 & 16.9 & 15.9 & 16.6 \\
\hline BIR1-16 & 46.3 & 323 & 121 & 16.8 & 15.5 & 19.9 \\
\hline BIR1-17 & 44.6 & 319 & 113 & 16.3 & 14.9 & 15.7 \\
\hline BIR1-18 & 45.0 & 333 & 127 & 16.1 & 15.4 & 16.5 \\
\hline BIR1-19 & 45.1 & 335 & 130 & 16.5 & 15.1 & 16.1 \\
\hline BIR1-20 & 44.7 & 331 & 130 & 16.6 & 15.3 & 16.7 \\
\hline BIR1-21 & 44.9 & 326 & 125 & 16.3 & 14.8 & 17.2 \\
\hline BIR1-22 & 43.5 & 320 & 125 & 15.8 & 14.9 & 15.7 \\
\hline Average ( $\pm 2 S D)$ & $44.3 \pm 2.3$ & $322 \pm 17$ & $127 \pm 13$ & $16.1 \pm 1.2$ & $15.0 \pm 0.8$ & $16.4 \pm 1.9$ \\
\hline \pm 2 SD $(\%)$ & 5.2 & 5.3 & 10 & 7.3 & 5.0 & 11 \\
\hline GEOREM ( $\mathbf{2 S D})$ & $43 \pm 4$ & $319 \pm 36$ & $119 \pm 16$ & $15.3 \pm 1.6$ & $15.6 \pm 1.8$ & $14.0 \pm 0.2$ \\
\hline
\end{tabular}


Table 2. Transition metal abundances (ppm) in USGS SRM BCR-1 obtained via the SA ICP-MS analysis technique. The GEOREM preferred values and the uncertainties ( $\pm 2 \mathrm{SD})$ are listed at the bottom.

\begin{tabular}{|c|c|c|c|c|c|c|}
\hline SRM & Sc & $\mathbf{V}$ & $\mathbf{C u}$ & $\mathbf{G a}$ & $\mathbf{Y}$ & $\mathbf{Z r}$ \\
\hline BCR1-01 & 32.07 & & 16.1 & 21.9 & 32.7 & 182 \\
BCR1-02 & 33.37 & 396 & 16.0 & 22.6 & 34.8 & 197 \\
BCR1-03 & 33.45 & 397 & 15.7 & 22.5 & 34.4 & 188 \\
BCR1-04 & 31.93 & 404 & & 22.5 & 33.9 & 186 \\
BCR1-05 & 32.84 & 394 & 15.8 & 22.4 & 34.5 & 193 \\
BCR1-06 & 33.22 & 401 & 15.7 & 22.6 & 34.2 & 195 \\
BCR1-07 & 32.71 & 399 & 16.2 & 22.5 & 34.1 & 187 \\
BCR1-08 & 33.09 & 396 & 15.9 & 22.3 & 35.0 & 196 \\
BCR1-09 & 33.06 & 402 & 15.9 & 22.6 & 35.3 & 198 \\
BCR1-10 & 32.46 & 401 & 16.3 & 22.3 & 34.0 & 185 \\
BCR1-11 & 32.64 & 392 & 15.8 & 22.0 & 33.3 & 187 \\
BCR1-12 & 32.82 & 399 & 15.8 & 22.6 & 33.6 & 192 \\
BCR1-13 & 31.83 & 389 & 15.8 & 21.9 & 33.1 & 184 \\
BCR1-14 & 33.04 & 398 & 16.1 & 22.5 & 34.2 & 191 \\
BCR1-15 & 32.89 & 398 & 16.0 & 22.5 & 34.3 & 192 \\
BCR1-16 & 32.43 & 408 & 16.9 & 22.4 & 34.1 & 190 \\
BCR1-17 & 32.98 & 393 & 15.6 & 22.0 & 33.1 & 183 \\
Average ( $\mathbf{2 S D})$ & $32.8 \pm 1.0$ & $398 \pm 10$ & $16.0 \pm 0.6$ & $22.3 \pm 0.5$ & $34.0 \pm 1.4$ & $190 \pm 10$ \\
2SD (\%) & 2.9 & 2.4 & 3.9 & 2.4 & 4.1 & 5.3 \\
\hline GEOREM ( $\mathbf{2 S D )}$ & $\mathbf{3 2 \pm 4}$ & $\mathbf{4 1 0 \pm 4 0}$ & $\mathbf{2 1 \pm 6}$ & $\mathbf{2 3 \pm 4}$ & $\mathbf{3 6} \pm \mathbf{4}$ & $\mathbf{1 8 9} \pm \mathbf{1 8}$ \\
\hline
\end{tabular}


Table 3. Transition metal abundances (ppm) in USGS SRM BHVO-1 obtained via the SA ICP-MS analysis technique. The GEOREM preferred values and the uncertainties $( \pm 2 \mathrm{SD})$ are listed at the bottom.

\begin{tabular}{|c|c|c|c|c|c|c|}
\hline SRM & Sc & $\mathrm{V}$ & $\mathrm{Cu}$ & $\mathbf{G a}$ & $\mathbf{Y}$ & $\mathbf{Z r}$ \\
\hline BHVO1-01 & 33.1 & 315 & 153 & 22.0 & 25.2 & 189 \\
\hline BHVO1-02 & 32.3 & 309 & 152 & 22.2 & 25.1 & 177 \\
\hline BHVO1-03 & 32.8 & 311 & 143 & 22.5 & 26.2 & 185 \\
\hline BHVO1-04 & 32.0 & 301 & 147 & 21.1 & 25.2 & 165 \\
\hline BHVO1-05 & 31.9 & 306 & 155 & 21.6 & 25.0 & 166 \\
\hline BHVO1-06 & 31.5 & 303 & 142 & 21.6 & 24.5 & 169 \\
\hline Average ( $\pm 2 S D)$ & $32.3 \pm 1.1$ & $306 \pm 9$ & $149 \pm 11$ & $21.8 \pm 1.0$ & $25.2 \pm 1.1$ & $175 \pm 20$ \\
\hline 2SD $(\%)$ & 3.5 & 2.8 & 7.2 & 4.7 & 4.3 & 12 \\
\hline GEOREM ( $( \pm 2 S D)$ & $31 \pm 4$ & $318 \pm 30$ & $137 \pm 18$ & $21 \pm 4$ & $26 \pm 4$ & $174 \pm 18$ \\
\hline
\end{tabular}


Table 4. $\mathrm{MgO}$ (wt. \%) and transition metal (ppm) abundances in whole rock samples from the Victoria's Lava Lake and in the calculated emplaced lava composition.

\begin{tabular}{|c|c|c|c|c|c|c|c|c|}
\hline Sample & Sc & $\mathbf{V}$ & $\mathbf{C u}$ & $\mathbf{G a}$ & $\mathbf{Y}$ & $\mathbf{Z r}$ & MgO & LOI \\
\hline $\mathbf{1 2 1 1 0}$ & 32.6 & 189 & 90.3 & 12.5 & 12.6 & 53.7 & 13.7 & 2.25 \\
$\mathbf{1 2 1 1 6}$ & 35.9 & 212 & 97.3 & 13.6 & 13.6 & 54.9 & 11.1 & 0.75 \\
$\mathbf{1 2 1 1 7}$ & 35.5 & 208 & 98.3 & 13.4 & 13.7 & 55.0 & 11.2 & 0.58 \\
$\mathbf{1 2 1 2 4}$ & 39.3 & 228 & 107 & 15.1 & 15.2 & 61.7 & 7.42 & 0.25 \\
01001_B & 22.6 & 131 & 59.6 & 8.10 & 7.98 & 31.2 & 25.4 & 2.78 \\
$\mathbf{1 2 0 0 1}$ & 22.4 & 135 & 60.0 & 8.15 & 7.80 & 31.7 & 26.4 & 2.99 \\
01103_B & 28.2 & 161 & 71.4 & 10.0 & 10.4 & 37.4 & 20.2 & 1.49 \\
01104_B & 26.7 & 155 & 73.4 & 9.86 & 10.0 & 40.0 & 21.6 & 1.27 \\
01105_B & 23.2 & 138 & 58.9 & 8.40 & 8.33 & 37.0 & 25.6 & 2.80 \\
12105 & 22.6 & 133 & 57.8 & 7.92 & 7.70 & 30.6 & 26.6 & 3.21 \\
01106_B & 27.7 & 155 & 68.2 & 9.40 & 9.77 & 36.4 & 21.4 & 1.42 \\
12106 & 27.3 & 153 & 68.7 & 9.71 & 9.32 & 36.4 & 21.5 & 1.06 \\
\hline Slope & $-1.232 \pm 30$ & $-0.1815 \pm 41$ & $-0.3953 \pm 90$ & $-2.778 \pm 62$ & $-2.755 \pm 62$ & & & \\
Intercept & $54.77 \pm 0.98$ & $49.59 \pm 0.48$ & $49.31 \pm 0.49$ & $48.51 \pm 0.47$ & $48.27 \pm 0.46$ & & & \\
MSWD & 3.4 & 1.2 & 0.82 & 0.45 & 0.67 & & & \\
\hline Emplaced lava & $32.4 \pm 1.0$ & $192 \pm 4$ & $87.3 \pm 1.9$ & $12.1 \pm 0.3$ & $12.1 \pm 0.3$ & $*$ & $14.8 \pm 0.3$ & \\
\hline
\end{tabular}

Note. Analyses were re-calculated on an anhydrous basis using the loss on ignition (LOI) data from Puchtel et al. (2016). The transition metal abundances in the emplaced lava were calculated using ISOPLOT regressions for each element versus the calculated $\mathrm{MgO}$ content of the emplaced lava from this study. The uncertainties used in the regression analyses were as follows: for the transition metals, $5 \%$ (2SD) as derived from the external reproducibility of analyses of USGS SRM BIR-1, BCR-1, and BHVO-1; for $\mathrm{MgO}, 1 \%$ (2SD) as derived from the long-term reproducibility of analyses of USGS SRM BIR-1 and BCR-1 (Puchtel et al., 2016). 
Table 5. Transition metal abundances in liquidus olivines and chromites from the Victoria's Lava Lake.

\begin{tabular}{|c|c|c|c|c|c|}
\hline Sample & Sc & $\mathbf{V}$ & $\mathbf{C u}$ & Ga & Y \\
\hline 12110 Olivine $(\mathbf{N}=\mathbf{1 4})$ & $5.84 \pm 0.18$ & $7.82 \pm 0.39$ & $4.25 \pm 0.19$ & $0.239 \pm 0.067$ & $0.122 \pm 0.025$ \\
\hline $\mathbf{1 2 0 0 1}$ Olivine $(\mathbf{N}=\mathbf{2 4})$ & $6.02 \pm 0.45$ & $7.31 \pm 0.39$ & $2.62 \pm 0.67$ & $0.115 \pm 0.043$ & $0.093 \pm 0.010$ \\
\hline $\mathbf{1 2 1 0 5}$ Olivine $(\mathbf{N}=\mathbf{4 8})$ & $6.12 \pm 0.21$ & $7.21 \pm 0.36$ & $2.87 \pm 0.42$ & $0.097 \pm 0.017$ & $0.093 \pm 0.009$ \\
\hline $\mathbf{1 2 1 0 5} / \mathbf{1}$ Olivine $(\mathbf{N}=\mathbf{4 7})$ & $4.66 \pm 0.14$ & $7.18 \pm 0.36$ & $2.72 \pm 0.43$ & $0.149 \pm 0.048$ & $0.079 \pm 0.010$ \\
\hline $\mathbf{1 2 1 1 0}$ Chromite $(\mathbf{N}=\mathbf{1 1})$ & $10.1 \pm 4.8$ & $1378 \pm 40$ & $12.1 \pm 3.9$ & $37.4 \pm 8.8$ & $1.76 \pm 1.05$ \\
\hline $\mathbf{1 2 0 0 1}$ Chromite $(\mathbf{N}=\mathbf{6 4})$ & $7.10 \pm 0.97$ & $1395 \pm 28$ & $9.47 \pm 3.15$ & $19.6 \pm 0.8$ & $0.407 \pm 0.554$ \\
\hline $\mathbf{1 2 1 0 5}$ Chromite $(\mathbf{N}=\mathbf{6 4})$ & $7.12 \pm 0.67$ & $1394 \pm 25$ & $9.26 \pm 2.04$ & $17.3 \pm 0.5$ & $0.092 \pm 0.060$ \\
\hline
\end{tabular}

Note. The data were obtained using the laser ablation ICP-MS technique. Each datum represents averages of multiple analyses performed on several mounts, as specified in the text. The uncertainties are $2 \mathrm{SE}$. 


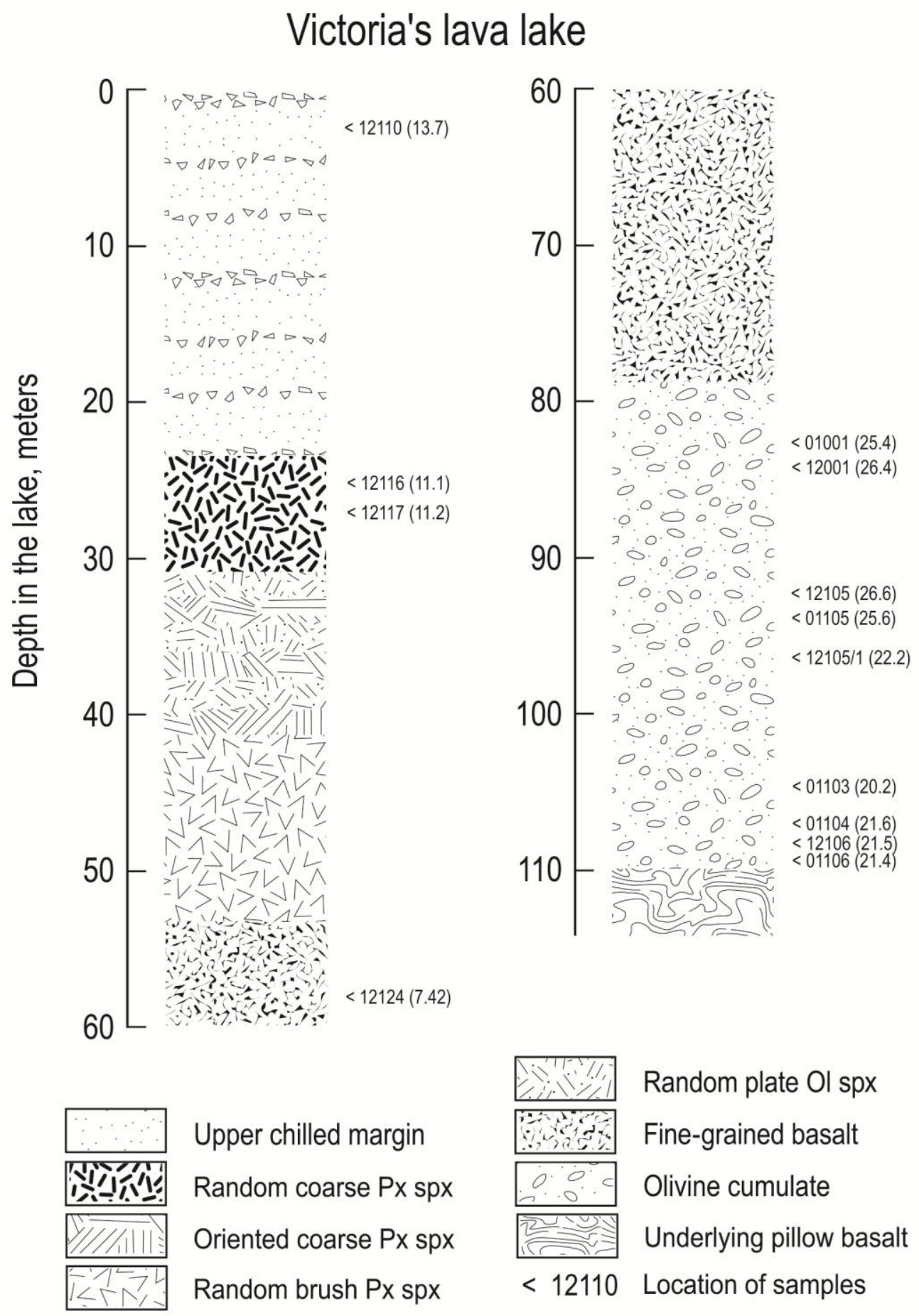

Fig. 1. 

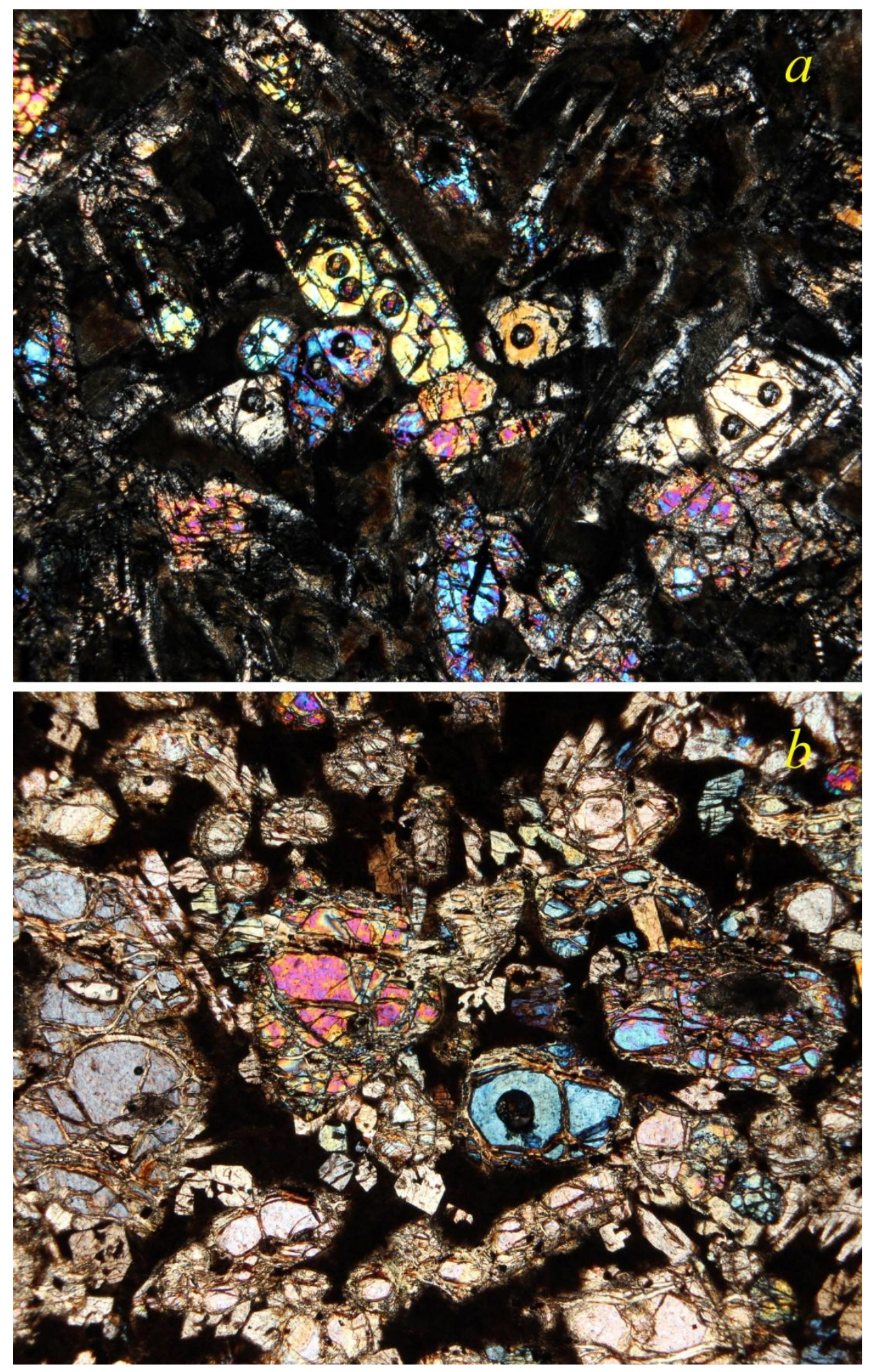

Fig. 2. 

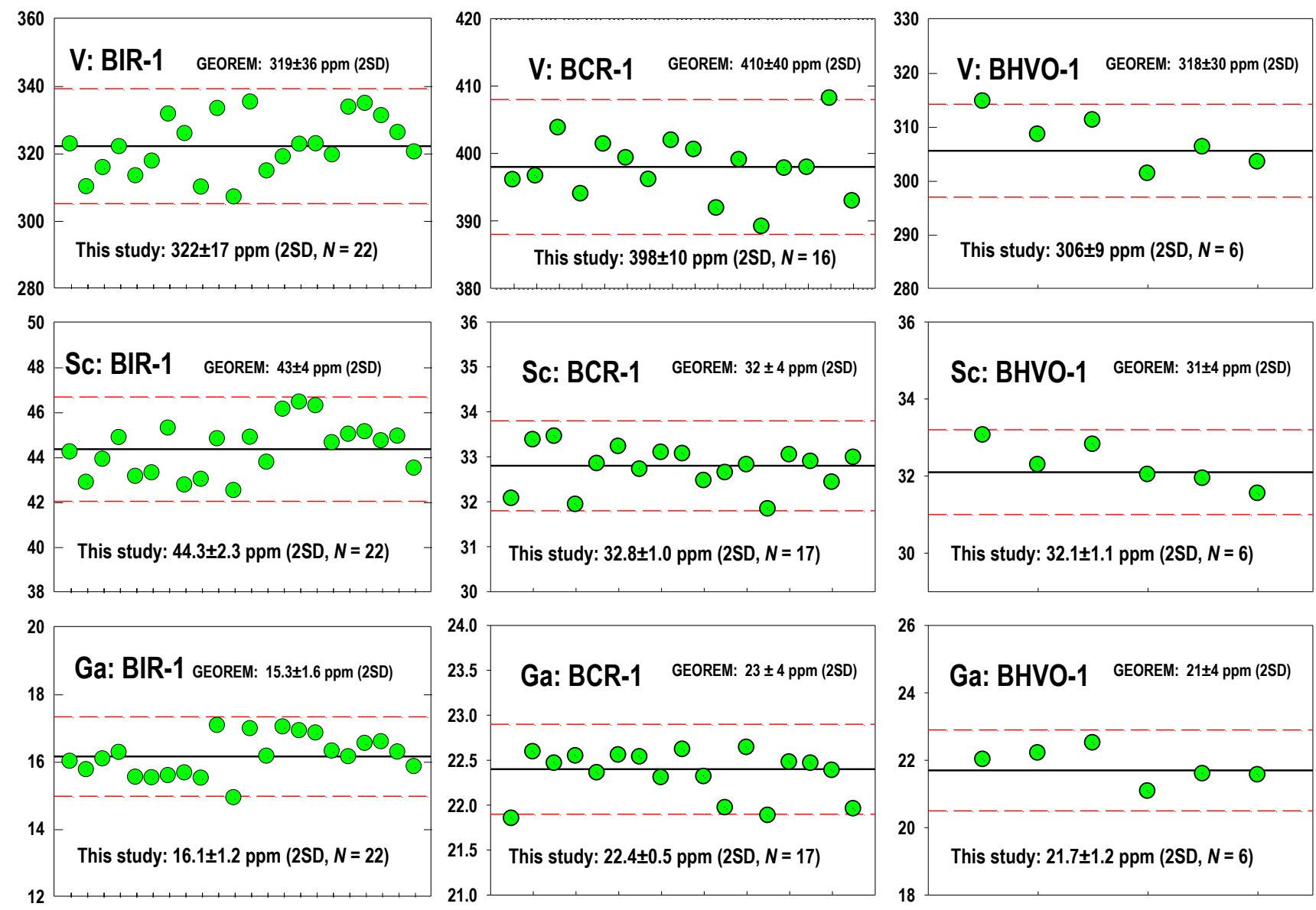

\section{Fig. 3.}



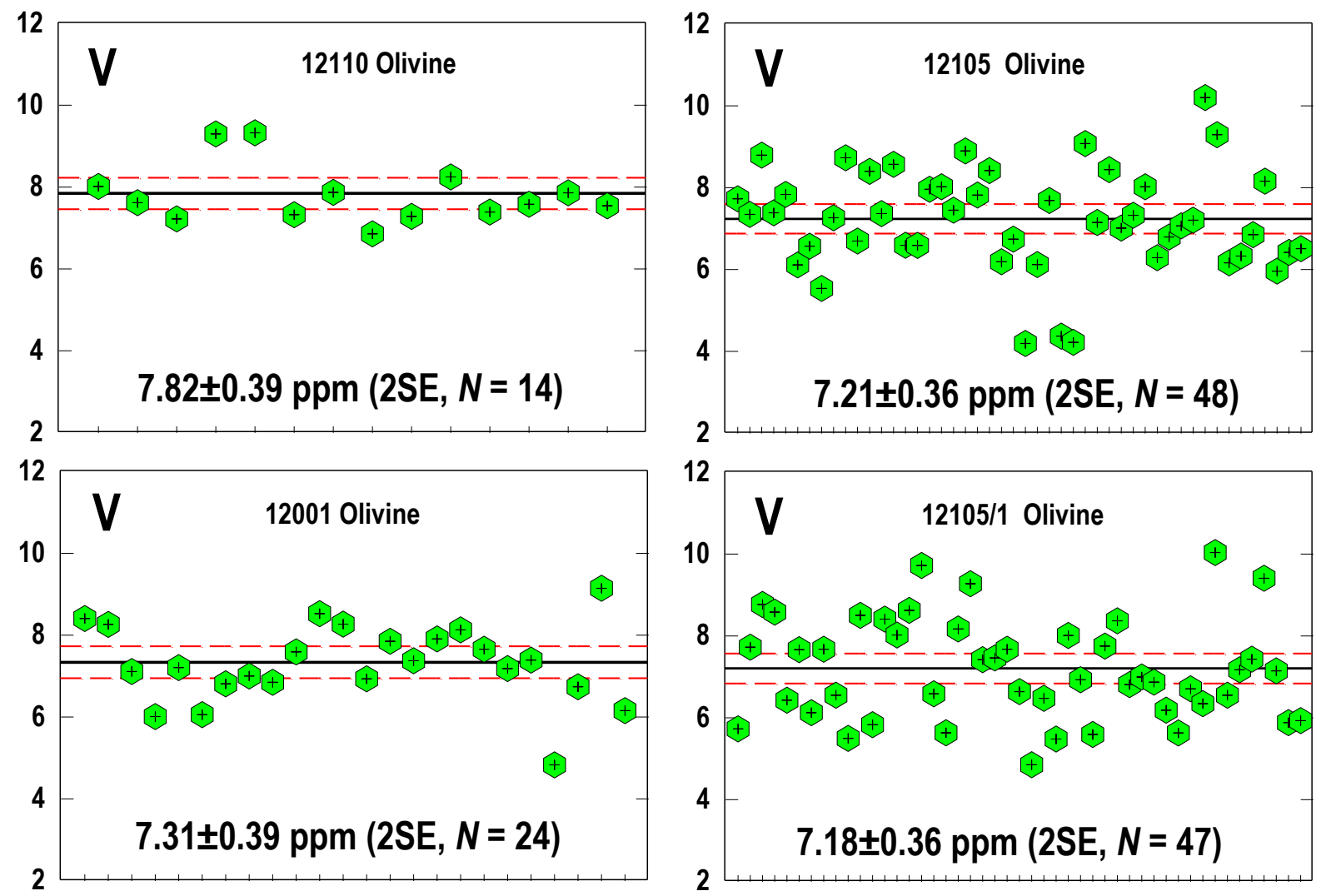

Fig. 4. 

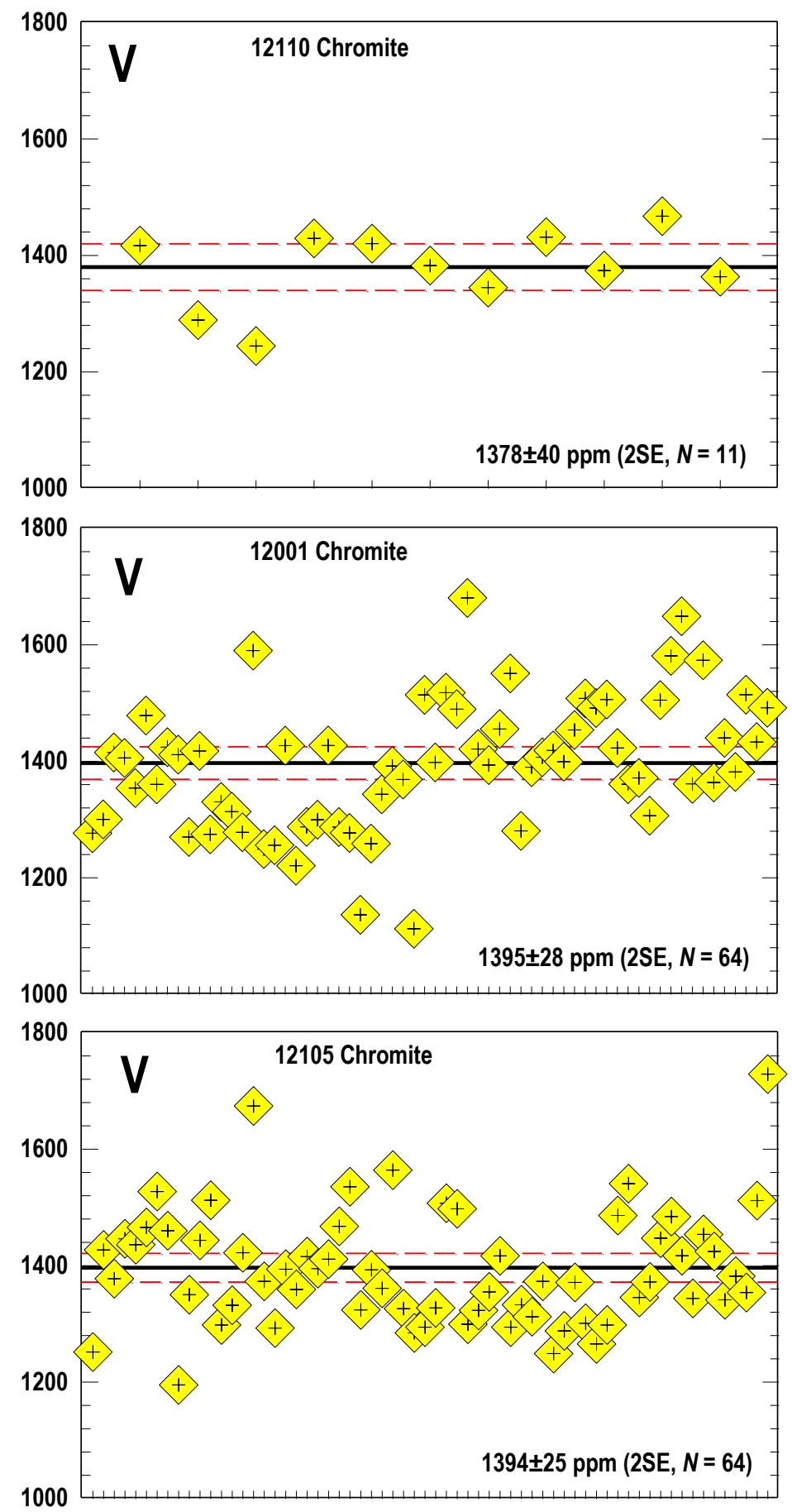

Fig. 5 

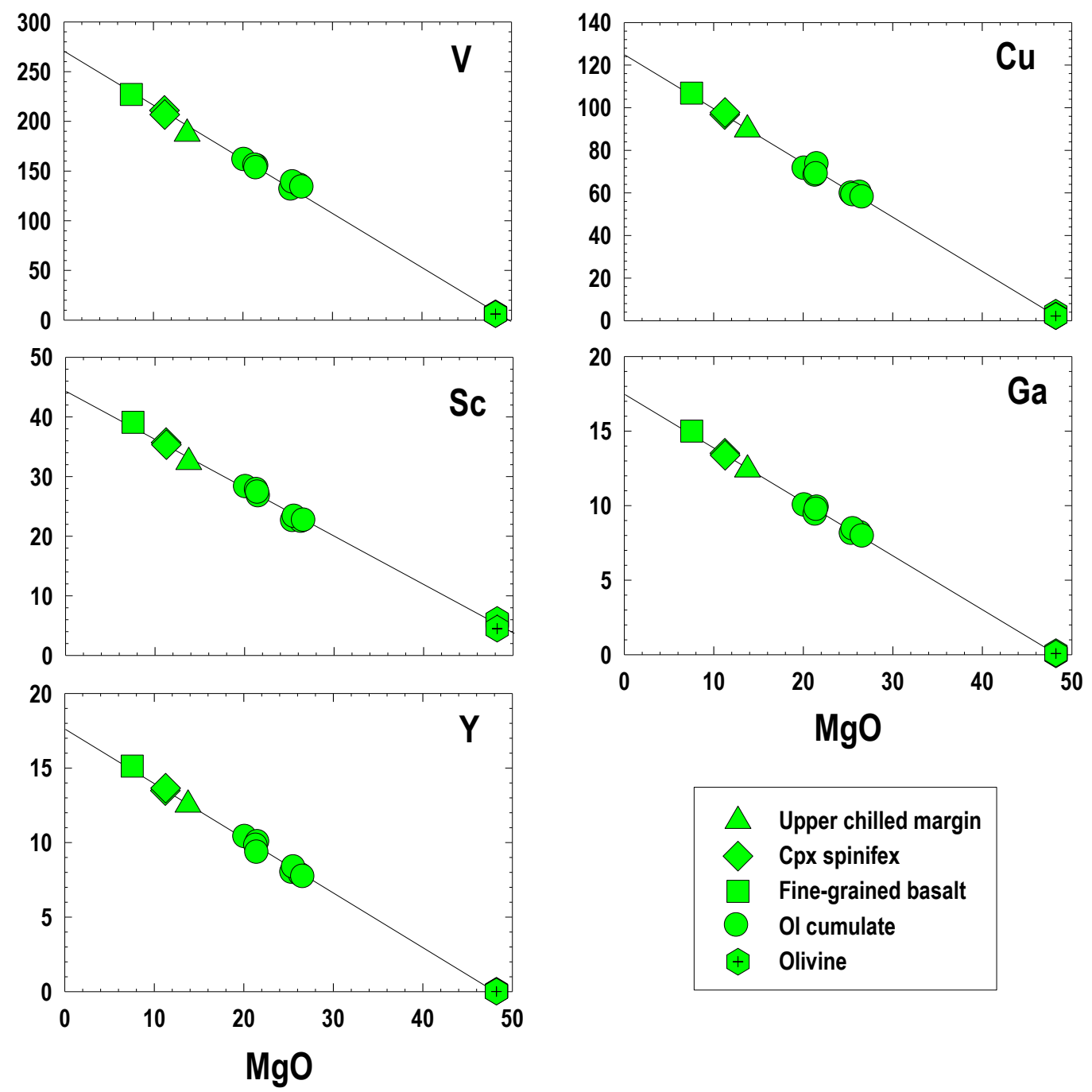

Fig. 6 